\title{
Clinical and radiological characteristics in patients with SARS- CoV-2-associated pneumonia. A descriptive study in a secondary care center
}

Juan J. Gómez-Piña1*, Emma R. González-Veyrand² and Roberto R. López Anguiano

${ }^{1}$ Internal Medicine Department, Hospital de Especialidades Dr. Antonio Fraga Mouret, Centro Médico Nacional La Raza; ${ }^{2}$ Department of Imaging, Hospital General de Zona no. 27 Alfredo Badallo; ${ }^{3}$ Department of Teaching, Hospital General de Zona no. 27 Alfredo Badallo. Instituto Mexicano del Seguro Social, Mexico City, Mexico

\begin{abstract}
Introduction: Real-time reverse-transcription polymerase chain reaction (RT-PCR) is the gold standard for establishing the diagnosis of coronavirus disease 2019 (COVID-19). Chest computed tomography (CCT), as a diagnostic complement, classifies tomographic findings according to the COVID-19 Reporting and Data System (CO-RADS). Objective: To determine CCT sensitivity and specificity for COVID-19 diagnosis. Methods: We reviewed RT-PCR results, as well as their respective CCTs. All CCTs were classified according to CO-RADS. CCT sensitivity and specificity were evaluated using the RT-PCR result that was closest to that of CCT as reference. Results: We included 412 patients, out of whom 277 were males (46-70 years) and 130 were females (45-71 years); with 181 negative and 231 positive tests, a sensitivity of $92.15 \%$ and specificity of $79.32 \%$ were obtained. Mortality increased after six hospitalization days, in males and in CO-RADS 4, 5 and 6 in comparison with CO-RADS 1, 2 and 3. Conclusions: Early diagnosis plays a decisive role in the prognosis of SARS-CoV-2-associated pneumonia. Although RT-PCR is current gold standard, false negatives are common; for this reason, CCT helps to confirm suspected cases, even at early stages. This imaging technique is an accessible and fundamental study for classification, diagnosis and prognosis.
\end{abstract}

KEY WORDS: CO-RADS. Clinical. Radiological. Characteristics. SARS-CoV-2.

\section{Características clínico-radiológicas en pacientes con neumonía por SARS-CoV-2, estudio descriptivo en un hospital de segundo nivel}

\section{Resumen}

Introducción: La reacción en cadena de la polimerasa con transcripción inversa en tiempo real (RT-PCR) es el estándar de oro para establecer el diagnóstico de enfermedad por coronavirus 2019 (COVID-19). La tomografía computarizada de tórax (TCT), como complemento diagnóstico, clasifica los hallazgos tomográficos de acuerdo con el sistema CO-RADS (COVID-19 Reporting and Data System). Objetivo: Determinar la sensibilidad y especificidad de la TCT para el diagnóstico de COVID-19. Métodos: Consultamos los resultados de RT-PCR, así como sus respectivas TCT. Todas las TCT se clasificaron de según CO-RADS. Se evaluó sensibilidad y especificidad de la TCT utilizando el resultado de RT-PCR más cercano de TCT como referencia. Resultados: Incluimos 412 pacientes, incluyendo 277 hombres (46-70 años) y 130 mujeres (45-71 años), con 181 pruebas negativas y 231 positivas; obteniendo sensibilidad del 92.15\% y especificidad del 79.32\%. La mortalidad aumentó después de 
seis días de hospitalización, en el sexo masculino y en CO-RADS 4, 5 y 6 en comparación con CO-RADS 1, 2 y 3. Conclusiones: El diagnóstico temprano es decisivo en el pronóstico de la neumonía SARS CoV 2. Aunque la RT-PCR es el estándar de oro actual, los falsos negativos son frecuentes, por lo que la TCT ayuda a confirmar los casos sospechosos, incluso en etapas tempranas. Este estudio de imagen es un estudio accesible y fundamental para la clasificación, diagnóstico y pronóstico.

PALABRAS CLAVE: CO-RADS. Clínico. Radiológico. Características. SARS-CoV-2.

\section{Introduction}

On December 31, 2019, in the city of Wuhan, China, an outbreak of atypical pneumonia caused by the severe acute respiratory syndrome coronavirus 2 (SARSCoV-2) was recognized, which in no time had a great impact on population survival, given that it became a pandemic, threatening public health and safety. Since this is a virus with respiratory tropism, it generates respiratory distress syndrome, which occurs more frequently in patients diagnosed with diabetes mellitus, hypertension, obesity and metabolic syndrome, and to a large extent affects the Mexican population, given that this is one of the deadliest viruses in our milieu. SARS-CoV-2 causes infection of pneumocytes, dendritic cells and macrophages, with replication being induced, especially in the parenchyma where the angiotensin-converting enzyme (ACE) II receptor is located, with the virus binding to the epithelium and starting its infection ${ }^{1}$.

Some SARS-CoV-2 characteristics have been identified; however, clinical characteristics have stood out with the presence of three clinical episodes: mild respiratory infection, pneumonia with evidence on chest computed tomography (CT) and severe pneumonia².

Given the rapid spread of the infection, auxiliary studies have been used for evidence of pneumonia to be generated, with chest CT being the best imaging study for identifying coronavirus disease 2019 (COVID-19), even previous clinical characteristics, up to two weeks after this ${ }^{3}$.

A radiological classification based on COVID-19 chest CT findings has been developed, which classifies the disease into five stages according to the degree of evolution: ultradevelopment, early and rapid progression, consolidation and dissipation. The first stage occurs between the first and second week after exposure in asymptomatic patients with consolidations, pulmonary nodules surrounded by ground glass opacities and air bronchogram. The second stage occurs one to two days after symptom onset, with single or multiple lesions, as well as interlobular septal thickening. The third stage occurs one week after symptom onset, with consolidations and air bronchogram. The fourth stage occurs after the second week of symptom onset, with lung consolidations reduction in size and density. The fifth stage occurs three weeks after pulmonary patches opacity was found, with bronchial walls thickening and intralobular and interlobular septal thickening ${ }^{4}$. Fibrosis has subsequently been found in most patients with ground glass opacity 5 .

COVID-19 diagnosis depends on imaging studies, such as simple chest CT scan, which allows typical lesions to be identified and classified according to the COVID-19 Reporting and Data System (CO-RADS) classification (Table 1), created by the Dutch Association of Radiologists (NVVR) ${ }^{6}$.

CT findings according to the CO-RADS classification provide a level of suspicion of COVID-19 pulmonary involvement, with levels that range from very low suspicion (CO-RADS 1) to very high suspicion (CORADS 5), in addition to identifying insufficient CT information (CO-RADS 0) or positive CT plus positive PCR test (CO-RADS 6). CO-RADS 0 cannot be assigned any of the five categories due to incomplete or poor-quality CT scans. CO-RADS 1 suggests a very low level of suspicion for COVID-19, CO-RADS 2 implies low suspicious lung involvement based on CT findings. Characteristics of centrilobular nodular pattern, lobar or segmental consolidation and lung cavitation can be found. CO-RADS 3 implies COVID-19 findings, characteristics of viral pneumonia, or non-infectious etiologies such as perihilar ground glass opacity, or ground glass images with smooth interlobular septal thickening with or without pleural effusion. CO-RADS 4 has typical COVID-19 characteristics; findings are like with another viral pneumonia, i.e., there is peribronchovascular inflammation. CO-RADS 5 has a very high level of COVID-19 suspicion with typical findings on $\mathrm{CT}$, as well as ground glass opacity, with or without consolidations, on visceral pleural surfaces?.

The use of fluorodeoxyglucose-positron-emission tomography/computed tomography (FDG-PET/CT) may be helpful to confirm SARS-CoV-2 infection ${ }^{8}$. Definitive diagnosis is made by real-time reverse 
Table 1. Main radiological findings on chest $\mathrm{CT}$ according to COVID-19 Reporting and Data System (CO-RADS) classification

\begin{tabular}{ll} 
Description & CT scan \\
\hline CO-RADS 1
\end{tabular}

Very low level of suspicion

Normal CT

CT without infection

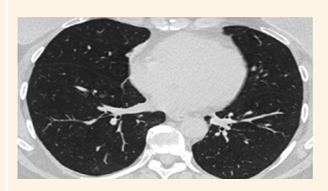

CO-RADS 2

Low level of suspicion

CT with no data of SARS-CoV-2

infection

Tree-in-bud pattern

Centrilobular nodular pattern

Lobar and segmented consolidation

Pulmonary cavitation

\section{CO-RADS 3}

CT with findings of viral pneumonia Peri-hilar ground-glass, ground glass opacity with interlobular septal thickening, pleural edema Ground glass radio-opacity Ground glass radio-opacity not located near pleurae
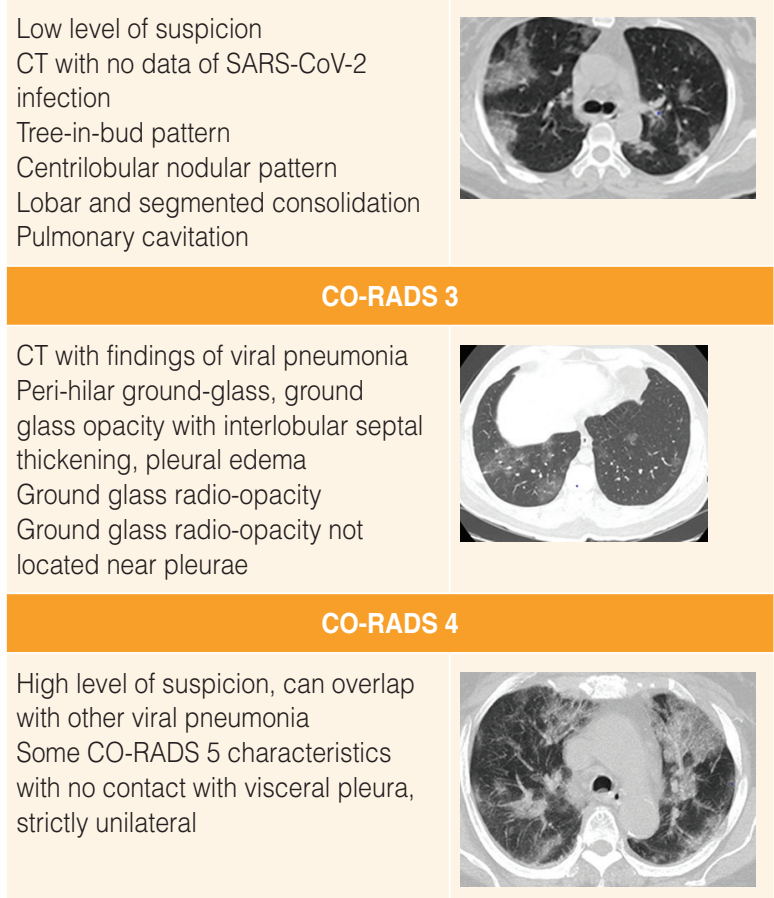

CO-RADS 5

Very high level of suspicion

Ground glass pattern with or without radio-opacities

Bilateral or multifocal radio-opacity, close to visceral pleura, including fissures

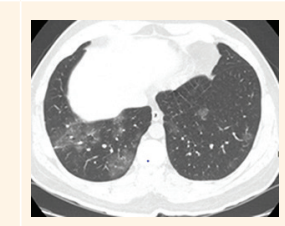

CT: computed tomography; SARS-CoV-2: severe acute respiratory syndrome coronavirus 2.

Adapted from Pan et al., 20205.

transcription polymerase chain reaction (RT-PCR) in samples obtained from oropharyngeal and nasopharyngeal swabs. This study has a sensitivity of $59 \%$ to $71 \%$ in comparison with repeated tests ${ }^{9}$.

Although COVID-19 typical CT findings are observed in confirmed patients, these characteristics can be found in patients with an initial RT-PCR false negative result ${ }^{10}$.

Patients with CO-RADS 5, lymphopenia and high serum ferritin, C-reactive protein, D-dimer and lactate dehydrogenase were found to have severe forms of COVID-19, in addition to having a C-reactive protein level $>10 \mathrm{mg} / \mathrm{L}$ and lymphopenia at levels lower than $0.8 \times 10^{9} / \mathrm{L}^{11}$.

In the Chinese population, the age range in patients diagnosed with COVID-19 who developed severe symptoms was $52-66$ years ${ }^{12,13}$. In the Italian population, the mortality rate increases with age by approximately $12 \%$ in patients older than 70 years and $20 \%$ in those older than 80 years ${ }^{14}$. Some studies indicate that the male gender is the most affected, and fever, cough and dyspnea were the main symptoms of the disease ${ }^{15}$.

Some reports refer that the majority of COVID-19 patients have diabetes mellitus, hypertension and previously-diagnosed heart diseases ${ }^{16}$.

C-reactive protein measurement reflects the magnitude of the systemic inflammatory syndrome at severe forms, with a "cytokine storm" being produced that leads to acute tissue damage and subsequent multisystem failure ${ }^{17}$. High mortality rates for intensive care patients have been documented in some reports from China, ranging from $81 \%$ to $97 \%{ }^{18}$. In addition, some reports refer a relationship between COVID-19 and acute kidney injury that increases in-hospital mortality ${ }^{19}$.

Some reports have noted that CT has a specificity lower than 50\%; however, current studies suggest that this specificity is actually higher ${ }^{20,21}$.

Given that RT-PCR sensitivity decreases after seven days of symptom onset, CT is suggested for diagnosing COVID-19 in patients with longer-lasting symptoms ${ }^{22}$. Currently used CO-RADS classification can detect more than $95 \%$ of patients with respiratory symptoms, and even a CO-RADS score $\geq 4$ was associated with a COVID-19 accurate diagnosis ${ }^{23}$.

The Radiological Society of North America (RSNA) classification is very similar to CO-RADS classification, which allows the use of both systems with almost the same results ${ }^{24}$.

The presence of obesity and high blood pressure has a significant association with serious diseases, which suggests a synergistic interaction between both conditions. Furthermore, there is an increased risk of progression to severe COVID-19 and longer viral shedding time in patients with non-alcoholic fatty liver disease ${ }^{25}$. On the other hand, other highly useful imaging studies have been described, with ultrasound being one of them and showing advantages such as absence of exposure of health workers to ionizing radiation, in addition to being a safe, fast and non-invasive diagnostic technique that is used at patient 


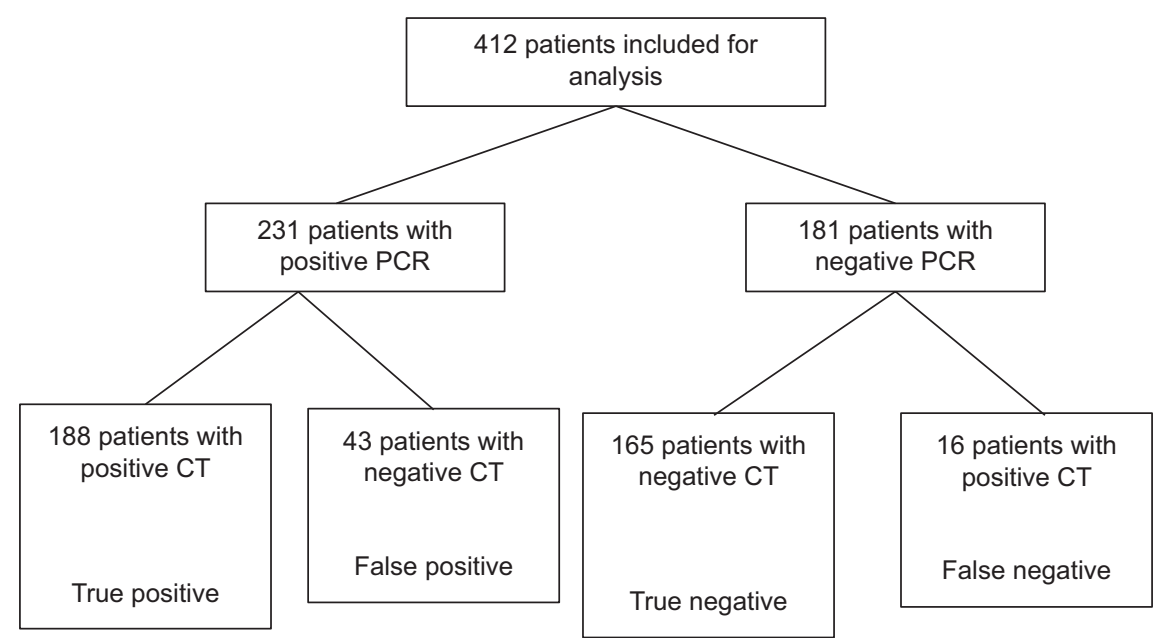

Figure 1. Study patients flowchart, with patients with positive and negative real-time reverse transcription polymerase chain reaction (RT-PCR), and patients with positive and negative computed tomography (CT).

bedside. Therefore, lung ultrasound is an effective alternative for diagnosing and monitoring patients with COVID-19-associated pneumonia ${ }^{26}$.

\section{Material and methods}

We made a search for all RT-PCR results of patients in our unit, with a suspected or confirmed diagnosis, from March 2020 to December 2020. Then, we searched for chest CT scans of patients with a previous PCR test, with patients older than 18 years of age, patients with suspected or confirmed SARS-CoV-2related atypical pneumonia being included; patients with viral pneumonia caused by viruses other than SARS-CoV-2, and patients without a definitive diagnosis of SARS-CoV-2-associated pneumonia were excluded. All CT scans were then classified according to CO-RADS criteria in order to determine probable or confirmed COVID-19 diagnosis. Statistical analysis was carried out using SPSS version 26 and Minitab version 18. Nominal variables were tested using Pearson's chi-square test. Chest CT diagnostic performance was evaluated based on diagnostic accuracy, sensitivity, specificity, positive predictive value and negative predictive value, taking as reference the RTPCR result that was closest to the CT findings (Fig. 1). Hospitalization days were analyzed on a survival graph using a Kaplan-Meier model.

\section{Results}

We recruited 412 patients with RT-PCR and chest CT, including 213 patients with positive RT-PCR, and
181 patients with negative RT-PCR; out of 213 patients with positive RT-PCR, 188 patients had positive chest CT for SARS-CoV-2 pneumonia and 43 patients had SARS-CoV-2 pneumonia negative chest CT; among 181 patients with negative RT-PCR, 165 patients had negative chest CT for SARS-CoV-2 pneumonia, and 16 patients had SARS-CoV-2 pneumonia positive chest CT. The main positive RT-PCRs correspond to people aged 44 to 69 years, and negative RT-PCRs are from people aged 49 to 73 years, with mortality increasing in the male gender during six days of hospital stay (Fig. 2). We obtained a sensitivity of $92.15 \%$ and specificity of $79.32 \%$, mainly associated with patients with a poor prognosis who underwent chest CT. In addition, mortality increases in the CORADS 4, 5 and 6 groups in comparison with CORADS 1, 2 and 3; however, a longer hospital stay was found in the CO-RADS 1, 2 and 3 group (Fig. 3).

\section{Discussion and conclusion}

COVID-19 is highly transmissible, with the risk of community-transmission being increased, which explains the high spread of the virus in our milieu ${ }^{27}$. Early diagnosis plays a critical role for controlling the spread of COVID-19; RT-PCR is current gold standard; however, being the main method used in our institutions, false negatives can be common when oral swabs are used; for this reason, multiple detection methods should be adopted for COVID-19 diagnosis to be confirmed, with the use of chest CT increasingly gaining importance due to its high sensitivity and specificity for pulmonary manifestations, even at early stages ${ }^{27,28}$. This tool is 


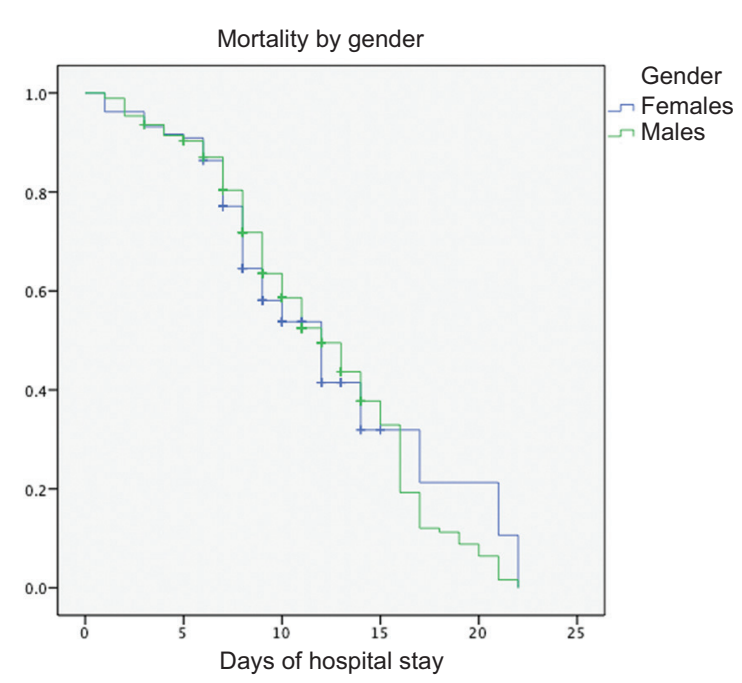

Figure 2. Kaplan-Meier plot showing mortality in the course of hospitalization days according to gender.

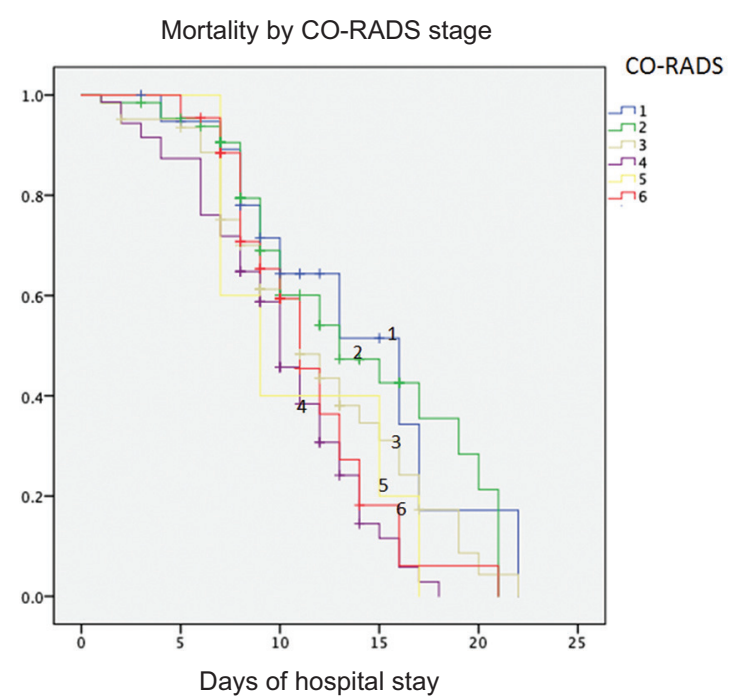

Figure 3. Kaplan-Meier plot showing mortality in the course of hospitalization days according to COVID-19 Reporting and Data System (CO-RADS) classification.

rapid and accessible for most people at secondary or tertiary care centers in our country, and useful for detecting COVID-19, especially in cases of RT-PCR false negatives. Chest CT can help to confirm or rule out suspected COVID-19 cases, classify them in the CORADS system, and act as a prognostic tool. Other studies in our country show sensitivity and specificity values that are closer to our findings, such as Velasco et al., who obtained a CT sensitivity of $89 \%$ and specificity of $66 \%$; however, they evaluated fewer patients than our study, which could explain the sensitivity and specificity differences between our studies.

\section{Funding}

There was no funding for this work.

\section{Conflict of interests}

The authors declare that they have no conflicts of interest.

\section{Ethical disclosures}

Protection of human and animal subjects. The authors declare that no experiments were performed on humans or animals for this research.

Confidentiality of data. The authors declare that they have followed the protocols of their work center on the publication of patient data.

Right to privacy and informed consent. The authors have obtained informed consent from the patients and/or subjects referred to in the article. This document is in the possession of the corresponding author.

\section{References}

1. Lu R, Zhao X, Li J, Niu P, Yang B, Wu H, et al. Genomic characterization and epidemiology of 2019 novel coronavirus: implications for virus origins and receptor binding. Lancet. 2020;395(10224):565-74.

2. The novel coronavirus pneumonia emergency response epidemiology team. Vital surveillances: the epidemiological characteristics of an outbreak of 2019 novel coronavirus diseases (COVID-19). China, 2020. China CDC Weekly. 2020;2(8):113-22.

3. Song F, Shi N, Shan F, Zhang Z, Shen J, Lu H. Emerging coronavirus (2019-nCoV) pneumonia. Radiology. 2020;295(1):210-7.

4. Jin YH, Cai L, Cheng ZS, Cheng H, Deng T, Fan YP. A rapid advice guideline for the diagnosis and treatment of 2019 novel coronavirus (2019nCoV) infected pneumonia (standard version). Mil Med Res. 2020;7(1):4

5. Pan Y, Guan H, Zhou S, Wang Y, Li Q, Zhu T. Initial CT findings and temporal changes in patients with the novel coronavirus pneumonia (2019-nCoV): A study of 63 patients in Wuhan, China. Eur Radiol. 2020;30(6):3306-9.

6. Prokop M, van Everdingen W, van Rees Vellinga T, Quarles van Ufford J, Stoger L, Beenen L, et al. CO-RADS - A categorical CT assessment scheme for patients with suspected COVID-19: definition and evaluation. Radiology. 2020;296(2):E97-E104.

7. Simpson S, Kay FU, Abbara S, Bhalla S, Chung JH, Chung M, et al. Radiological Society of North America Expert Consensus Statement on Reporting Chest CT Findings Related to COVID-19. Endorsed by the Society of Thoracic Radiology, the American College of Radiology, and RSNA. Radiol Cardiothorac Imaging. 2020;2(2):e200152.

8. Maurea S, Mainolfi CG, Bombace C, Annunziata A, Attanasio L, Petretta M, et al. FDG-PET/CT imaging during the Covid-19 emergency: a southern Italian perspective. Eur J Nucl Med Mol Imaging. 2020;47(11):2691-7.

9. Pang J, Wang MX, Ang IYH, Tan SHX, Lewis RF, Chen Jl, et al. Potential rapid diagnostics, vaccine and therapeutics for 2019 novel coronavirus (2019-nCoV): a systematic review. J Clin Med. 2020;9(3):623.

10. Xie X, Zhong Z, Zhao W, Zheng C, Wang F, Liu J. Chest CT for typical 2019-nCoV pneumonia: relationship to negative RT-PCR testing. Radiology. 2020;296(2):E41-E45.

11. El Aidaoui K, Haoudar A, Khalis M, Kantri A, Ziati J, El Ghanmi A, et al. Predictors of severity in Covid-19 patients in Casablanca, Morocco. Cureus. 2020;12(9):e10716 
12. Wang D, Hu B, Hu C, Zhu F, Liu X, Zhang J, et al. Clinical characteristics of 138 hospitalized patients with 2019 novel coronavirus-infected pneumonia in Wuhan, China. JAMA. 2020;323(11):1061-9.

13. Yang $X, Y u Y, X u$ J, Shu H, Xia J, Liu H, et al. Clinical course and outcomes of critically ill patients with SARS-CoV-2 pneumonia in Wuhan, China: a single-centered, retrospective, observational study. Lancet Respir Med. 2020;8:475-81.

14. Livingston E, Bucher K. Coronavirus disease 2019 (COVID-19) in Italy. JAMA. 2020:323:1335.

15. Zheng Z, Peng F, Xu B, Zhao J, Liu H, Peng J, et al. Risk factors of critical \& mortal COVID-19 cases: a systematic literature review and meta-analysis. J Infect. 2020;81:e16-e25.

16. Huang $\mathrm{C}$, Wang $\mathrm{Y}$, Li X, Ren L, Zhao J, Hu Y, et al. Clinical features of patients infected with 2019 novel coronavirus in Wuhan, China. Lancet. 2020;395:497-506.

17. Henry BM, de Oliveira MHS, Benoit S, Plebani M, Lippi G. Hematologic, biochemical and immune biomarker abnormalities associated with severe illness and mortality in coronavirus disease 2019 (COVID-19): a meta-analysis. Clin Chem Lab Med. 2020;58:1021-8.

18. Liu W, Tao Z-W, Wang L, Yuan ML, Liu K, Zhou L, et al. Analysis of factors associated with disease outcomes in hospitalized patients with 2019 novel coronavirus disease. Chin Med J (Engl). 2020;133:1032-8.

19. Cheng Y, Luo R, Wang K, Zhang M, Wang Z, Dong L, et al. Kidney disease is associated with in-hospital death of patients with COVID-19. Kidney Int. 2020;97:829-38.

20. Kim H, Hong H, Yoon SH. Diagnostic performance of CT and reverse transcriptase-polymerase chain reaction for coronavirus disease 2019: A meta-analysis. Radiology. 2020;296(3):E145-E155.
21. Himoto Y, Sakata A, Kirita M, Hiroi T, Kobayashi KI, Kubo K, et al. Diagnostic performance of chest CT to differentiate COVID-19 pneumonia in non-high-epidemic area in Japan. Jpn J Radiol. 2020;38(5):400-6.

22. Tahamtan A, Ardebili A. Real-time RT-PCR in COVID-19 detection: issues affecting the results. Expert Rev Mol Diagn. 2020;20(5):453-4.

23. Schalekamp S, Bleeker-Rovers CP, Beenen LFM, Quarles van Ufford HME, Gietema HA, Stöger JL, et al. Chest CT in the Emergency Department for diagnosis of COVID-19 pneumonia: Dutch experience. Radiology. 2021;298(2):E98-E106.

24. Palomar-Lever A, Barraza G, Galicia-Alba J, Echeverri-Bolaños M, Escarria-Panesso R, Padua-Barrios J, et al. Hepatic steatosis as an independent risk factor for severe disease in patients with COVID-19: A computed tomography study. JGH Open. 2020;4(6):1102-7.

25. Zhang W, Du RH, Li B, Zheng XS, Yang XL, Hu B, et al. Molecular and serological investigation of 2019-nCoV infected patients: implication of multiple shedding routes. Emerg Microbes Infect. 2020;9:386-9.

26. Karacaer C, Karabay O, Gunduz Y, Yaylacı S, Guclu E. Correlation of lung ultrasound and computed tomography findings in COVID-19 pneumonia. J Coll Physicians Surg Pak. 2020;30(10):147-52.

27. Li T. Diagnosis and clinical management of severe acute respiratory syndrome coronavirus 2 (SARS-CoV-2) infection: an operational recommendation of Peking Union Medical College Hospital (V2.0). Emerg Microbes Infect. 2020;9:582-5.

28. Xie X, Zhong Z, Zhao W, Zheng C, Wang F, Liu J. Chest CT for typical 2019-nCoV pneumonia: relationship to negative RT-PCR testing. Radiology. 2020;296:E41-E45. 